\title{
Silica Sulfuric Acid as an Efficient Heterogeneous Catalyst for the Solvent-Free Synthesis of 1-Substituted 1H-1,2,3,4-Tetrazoles
}

\author{
Davood Habibi, Hiva Nabavi, and Mahmoud Nasrollahzadeh \\ Department of Organic Chemistry, Faculty of Chemistry, Bu-Ali Sina University, Hamedan 6517838683, Iran \\ Correspondence should be addressed to Davood Habibi; davood.habibi@gmail.com
}

Received 4 June 2012; Revised 17 July 2012; Accepted 18 July 2012

Academic Editor: Stojan Stavber

Copyright (C) 2013 Davood Habibi et al. This is an open access article distributed under the Creative Commons Attribution License, which permits unrestricted use, distribution, and reproduction in any medium, provided the original work is properly cited.

Silica sulfuric acid (SSA) was found to be an efficient heterogeneous catalyst for the synthesis of 1-substituted 1H-1,2,3,4-tetrazoles from the reaction of primary amines with triethyl orthoformate and sodium azide under thermal and solvent-free conditions.

\section{Introduction}

Application of the tetrazole compounds including 1substituted tetrazoles [1-3] has increased rapidly over the past few years for different purposes. For example they have been used in coordination chemistry, medicinal chemistry, agriculture, photography, and preparation of nitrogen-containing compounds $[4,5]$.

In general, the most direct and versatile method of the synthesis of tetrazoles is the cycloaddition between nitriles, cyanates and cyanamides, and azides [4, 6-11].

1 -substituted tetrazoles are generally synthesized by reaction of isocyanides with large excess amounts of dangerous and harmful hydrazoic acid $[12,13]$ or trimethyl azide [14]. The other methods include addition of amines or their salts to sodium azide and orthocarboxylic acid ester in acetic acid or trifluoroacetic acid $[15,16]$. Su and coworkers have reported the synthesis of 1 -substituted tetrazoles using $\mathrm{Yb}(\mathrm{OTf})_{3}$ in volatile organic solvents [17].

All of these known methods suffered from some limitations such as low yields, drastic reaction conditions, the use of expensive and toxic metal catalysts, tedious workup, complex isolation and recovery procedures, the use of excessive amounts of glacial acetic acid or trifluoroacetic acid (an expensive solvent), the use of high boiling point solvent such as DMF (which is soluble in both organic solvents and water; thus its removing from the reaction mixture is difficult) and even the need for excess amounts of dangerous and harmful hydrazoic acid $[4,6-8,15,16]$. Therefore, the development of a more efficient and convenient method for the synthesis of 1-substituted tetrazoles under solvent-free conditions still remains an active research area.

During the last decade many academic and industrial processes shifted towards the development of new technologies in synthetic organic chemistry using solid acid catalysts [18-22]. Among various silica-based heterogeneous catalysts, silica sulfuric acid (SSA) has advantages of low cost, ease of preparation and recyclability, and is insoluble in all organic solvents.

\section{Experimental}

2.1. General Procedure for Preparation of the 1-Substituted Tetrazoles. A mixture of amine $(2.0 \mathrm{mmol}), \mathrm{NaN}_{3}$ $(2.0 \mathrm{mmol})$, triethyl orthoformate $(2.4 \mathrm{mmol})$, and SSA $(0.02 \mathrm{~g})$ was taken in a $25 \mathrm{~mL}$ round bottom flask equipped with a condenser under a well-ventilated fume hood and heated at $120^{\circ} \mathrm{C}$ for the appropriate time with vigorous stirring (Table 1). After completion (as monitored by TLC), the reaction mixture was diluted with cold water $(5 \mathrm{~mL})$ and extracted with ethyl acetate $(3 \times 10 \mathrm{~mL})$. The catalyst was removed by filtration, and the combined organic layers were washed with brine and dried over anhydrous $\mathrm{Na}_{2} \mathrm{SO}_{4}$. After concentration, a crystallization step was performed using EtOAc-hexane to afford the pure product. All the products are known compounds, and the spectral data and melting points were identical to those reported in the literature $[14-16,23,24]$. 
TABLE 1: Synthesis of 1-substituted 1H-1,2,3,4-tetrazoles from the reaction of primary amines, sodium azide, and triethyl orthoformate in the presence of SSA at $120^{\circ} \mathrm{C}$ and in solvent-free conditions.

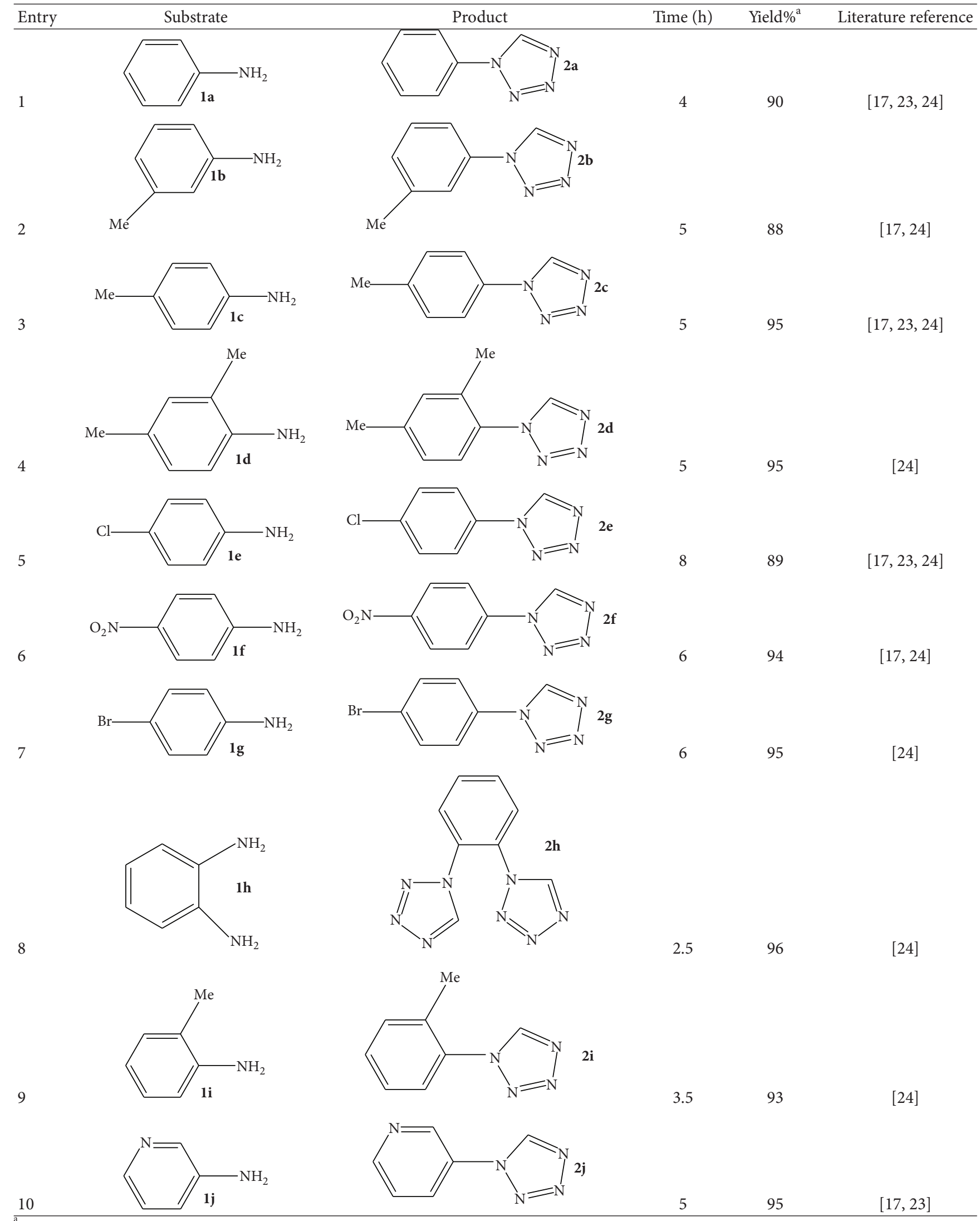

Yield refers to the pure isolated product. 


$$
\mathrm{RNH}_{2}+\mathrm{CH}(\mathrm{OEt})_{3}+\mathrm{NaN}_{3} \stackrel{\mathrm{SSA}, 120^{\circ} \mathrm{C}}{\text { Solvent-free }}
$$

SCHEME 1

\section{Results and Discussion}

In continuation of our researches on the synthesis of nitrogen-containing compounds $[10,11,24-31]$, we put forward a mild, efficient, and convenient method for the synthesis of 1-substituted $1 \mathrm{H}-1,2,3,4$-tetrazoles from a wide variety of primary amines with sodium azide and orthoformate in the presence of SSA as an efficient heterogeneous catalyst at $120^{\circ} \mathrm{C}$ for appropriate time in solvent-free condition (Scheme 1).

First, we examined a variety of structurally divergent aniline possessing a wide range of functional groups to understand the scope and generality of the SSA-promoted cycloaddition reaction to form the 1-substituted tetrazoles, and the results are summarized in Table 1.

Treatment of the heteroaromatic 3-aminopyridine with orthoformate and sodium azide at $120^{\circ} \mathrm{C}$ for $5 \mathrm{~h}$ also afforded the corresponding tetrazole in an excellent yield (Table 1, entry 10). Due to the presence of two $\mathrm{NH}_{2}$ groups, $\mathbf{1 h}$ interestingly afforded the double-addition product (Table 1, entry 8).

In a typical experiment, after completion of the reaction, SSA was isolated from the reaction mixture by simple filtration. The reusability of the catalyst was assessed after activating the catalyst at $80^{\circ} \mathrm{C}$ for $5 \mathrm{~h}$. Then it was reused three times successively with consistent activity, indicating high activity of the catalyst. This reusability demonstrates the high stability and turnover of SSA under operating condition.

The products were characterized by NMR, FT-IR, elemental analysis (CHN), and melting points. The 1-substituted tetrazoles are generally acidic substances and the relevant proton signal will be shifted to downfield (see ${ }^{1} \mathrm{H}$ NMR data), so the peak at $\delta=7.80-8.30 \mathrm{ppm}$ can be attributed to the proton of the tetrazole ring. ${ }^{13} \mathrm{C}$ NMR spectra displayed signals about $\delta=147-157$ ppm for C5 of the tetrazole ring $[10,11,24]$.

\section{Conclusion}

We applied an efficient methodology for synthesis of the 1substituted tetrazoles using SSA as a heterogeneous catalyst. All reactions were performed under solvent-free conditions (from the standpoint of green chemistry and industry, both are important due to the reduced pollution, low cost, and simplicity in processing and handling) with high yields and a simple workup that no chromatographic procedure is necessary to get the pure compounds. The SSA catalyst can be recovered by simple filtration and reused without the loss of activity. This methodology may find widespread application in organic synthesis for preparation of the tetrazoles. Further studies are in progress.

\section{Acknowledgments}

The authors are thankful to the Bu-Ali Sina University, Hamedan 6517838683, Iran for the support of this work.

\section{References}

[1] H. Singh, A. Singh Chawla, V. K. Kapoor, D. Paul, and R. K. Malhotra, "4 medicinal chemistry of tetrazoles," Progress in Medicinal Chemistry, vol. 17, pp. 151-183, 1980.

[2] M. J. Genin, D. A. Allwine, D. J. Anderson et al., "Substituent effects on the antibacterial activity of nitrogen-carbon- linked (azolylphenyl)oxazolidinones with expanded activity against the fastidious gram-negative organisms Haemophilus influenzae and Moraxella catarrhalis," Journal of Medicinal Chemistry, vol. 43, no. 5, pp. 953-970, 2000.

[3] P. Ward, D. R. Armour, D. E. Bays et al., "Discovery of an orally bioavailable NK1 receptor antagonist, (2S,3S)-(2methoxy-5-tetrazol-1-ylbenzyl)(2-phenylpiperidin-3-yl)amine (GR203040), with potent antiemetic activity," Journal of Medicinal Chemistry, vol. 38, no. 26, pp. 4985-4992, 1995.

[4] R. Jason Herr, "5-Substituted-1H-tetrazoles as carboxylic acid isosteres: medicinal chemistry and synthetic methods," Bioorganic and Medicinal Chemistry, vol. 10, no. 11, pp. 3379-3393, 2002.

[5] V. A. Ostrovskii, G. I. Koldobskii, and R. E. Trifonov, "Tetrazoles," in Comprehensive Heterocyclic Chemistry III, A. R. Katrizky, C. A. Ramsden, E. F. V. Scriven, and R. J. K. Taylor, Eds., vol. 6, pp. 257-424, Elsevier, Oxford, UK, 2008.

[6] F. R. Benson, "The chemistry of the tetrazoles," Chemical Reviews, vol. 41, no. 1, pp. 1-61, 1947.

[7] G. I. Koldobskii, V. A. Ostrovskii, and V. S. Popavskii, "Advances in the chemistry of tetrazoles (review)," Chemistry of Heterocyclic Compounds, vol. 17, no. 10, pp. 965-988, 1981.

[8] P. K. Kadaba, "ole of Protic and Dipolar Aprotic Solvents in Heterocyclic Syntheses via 1,3-Dipolar Cycloaddition Reactions," Synthesis, no. 2, pp. 71-84, 1973.

[9] A. R. Katritzky, B. V. Rogovoy, and K. V. Kovalenko, "A general route to 5-aminotetrazoles," Journal of Organic Chemistry, vol. 68, no. 12, pp. 4941-4943, 2003.

[10] M. Nasrollahzadeh, Y. Bayat, D. Habibi, and S. Moshaee, " $\mathrm{FeCl}_{3}-\mathrm{SiO}_{2}$ as a reusable heterogeneous catalyst for the synthesis of 5-substituted $1 H$-tetrazoles via [2+3] cycloaddition of nitriles and sodium azide," Tetrahedron Letters, vol. 50, no. 31, pp. 4435-4438, 2009.

[11] D. Habibi and M. Nasrollahzadeh, "Silica-supported ferric chloride $\left(\mathrm{FeCl}_{3}-\mathrm{SiO}_{2}\right)$ : an efficient and recyclable heterogeneous catalyst for the preparation of arylaminotetrazoles," Synthetic Communications, vol. 40, no. 21, pp. 3159-3167, 2010.

[12] D. M. Zimmerman and R. A. Olofson, "The rapid synthesis of 1-substituted tetrazoles," Tetrahedron Letters, vol. 10, no. 58, pp. 5081-5084, 1969.

[13] F. G. Fallon and R. M. Herbst, "Synthesis of 1-substituted tetrazoles," Journal of Organic Chemistry, vol. 22, no. 8, pp. 933-936, 1957.

[14] T. Jin, S. Kamijo, and Y. Yamamoto, "Synthesis of 1-substituted tetrazoles via the acid-catalyzed [3+2] cycloaddition between isocyanides and trimethylsilyl azide," Tetrahedron Letters, vol. 45, no. 51, pp. 9435-9437, 2004.

[15] Y. Satoh and N. Marcopulos, "Application of 5-lithiotetrazoles in organic synthesis," Tetrahedron Letters, vol. 36, no. 11, pp. 1759-1762, 1995. 
[16] A. K. Gupta, C. H. Song, and C. H. Oh, "1-(2-Iodophenyl)$1 H$-tetrazole as a ligand for Pd(II) catalyzed Heck reaction," Tetrahedron Letters, vol. 45, no. 21, pp. 4113-4116, 2004.

[17] W.-K. Su, Z. Hong, W.-G. Shan, and X.-X. Zhang, "A facile synthesis of 1-substituted-1H-1,2,3,4-tetrazoles catalyzed by ytterbium triflate hydrate," The Journal of Organic Chemistry, no. 12, pp. 2723-2726, 2006.

[18] G. Thirunarayanan and G. Vanangamudi, "Synthesis of some 4bromo-1-naphthyl chalcones using silica-sulfuric acid reagent under solvent free conditions," Arkivoc, vol. 2006, no. 12, pp. 58-64, 2006.

[19] D. M. Pore, U. V. Desai, T. S. Thopate, and P. P. Wadgaonkar, "A mild, expedient, solventless synthesis of bis(indolyl)alkanes using silica sulfuric acid as a reusable catalyst," Arkivoc, vol. 2006, no. 12, pp. 75-80, 2006.

[20] H. Wu, Y. Shen, L. Y. Fan, Y. Wan, and D. Q. Shi, "Solid silica sulfuric acid (SSA) as a novel and efficient catalyst for acetylation of aldehydes and sugars," Tetrahedron, vol. 62, no. 34, pp. 7995-7998, 2006.

[21] J. D. Moore, R. H. Herpel, J. R. Lichtsinn, D. L. Flynn, and P. R. Hanson, "ROMP-generated oligomeric sulfonyl chlorides as versatile soluble scavenging agents," Organic Letters, vol. 5, no. 2, pp. 105-107, 2003.

[22] M. A. H. Fahmy and T. R. J. Fukuto, "Convenient method for synthesis of (hydroxymethyl)carbamates," Journal of Agricultural andFood Chemistry, vol. 20, p. 168, 1972.

[23] T. M. Potewar, S. A. Siddiqui, R. J. Lahoti, and K. V. Srinivasan, "Efficient and rapid synthesis of 1-substituted-1H-1,2,3,4tetrazoles in the acidic ionic liquid 1-n-butylimidazolium tetrafluoroborate," Tetrahedron Letters, vol. 48, no. 10, pp. 1721-1724, 2007.

[24] D. Habibi, M. Nasrollahzadeh, and T. A. Kamali, "Green synthesis of the 1-substituted $1 H$-1,2,3,4-tetrazoles by application of the Natrolite zeolite as a new and reusable heterogeneous catalyst," Green Chemistry, vol. 13, no. 12, pp. 3499-3504, 2011.

[25] D. Habibi, M. Nasrollahzadeh, A. R. Faraji, and Y. Bayat, "Efficient synthesis of arylaminotetrazoles in water," Tetrahedron, vol. 66, no. 21, pp. 3866-3870, 2010.

[26] M. Nasrollahzadeh, D. Habibi, Z. Shahkarami, and Y. Bayat, "A general synthetic method for the formation of arylaminotetrazoles using natural natrolite zeolite as a new and reusable heterogeneous catalyst," Tetrahedron, vol. 65, no. 51, pp. 10715-10719, 2009.

[27] T. A. Kamali, D. Habibi, and M. Nasrollahzadeh, "Synthesis of 6-substituted imidazo[2,1-b][1,3]thiazoles and 2-substituted imidazo[2,1-b][1,3]benzothiazoles via $\mathrm{pd} / \mathrm{cu}$-mediated sonogashira coupling," Synlett, no. 16, pp. 2601-2604, 2009.

[28] T. A. Kamali, M. Bakherad, M. Nasrollahzadeh, S. Farhangi, and D. Habibi, "Synthesis of 6-substituted imidazo[2,1-b]thiazoles via $\mathrm{Pd} / \mathrm{Cu}$-mediated Sonogashira coupling in water," Tetrahedron Letters, vol. 50, no. 39, pp. 5459-5462, 2009.

[29] D. Habibi and M. Nasrollahzadeh, "Synthesis of arylaminotetrazoles by $\mathrm{ZnCl}_{2} / \mathrm{AlCl}_{3} /$ silica as an efficient heterogeneous catalyst," Monatshefte für Chemie, vol. 143, no. 6, pp. 925-930, 2012.

[30] D. Habibi, M. Nasrollahzadeh, and Y. Bayat, " $\mathrm{AlCl}_{3}$ as an effective lewis acid for the synthesis of arylaminotetrazoles," Synthetic Communications, vol. 41, no. 14, pp. 2135-2145, 2011.

[31] D. Habibi and M. Nasrollahzadeh, "Zno as an effective and reusable heterogeneous catalyst for the synthesis of arylaminotetrazoles," Synthetic Communications, vol. 42, no. 14, pp. 2023-2032, 2012. 

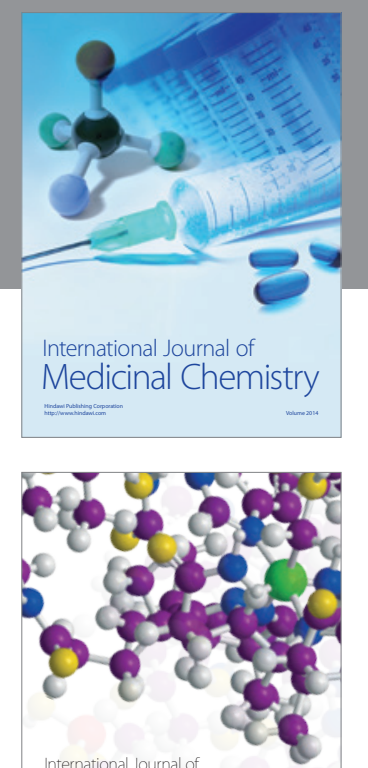

\section{Carbohydrate} Chemistry

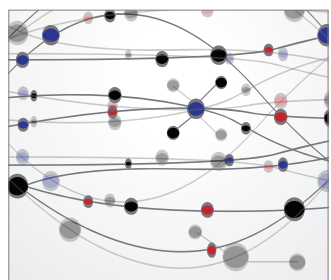

The Scientific World Journal
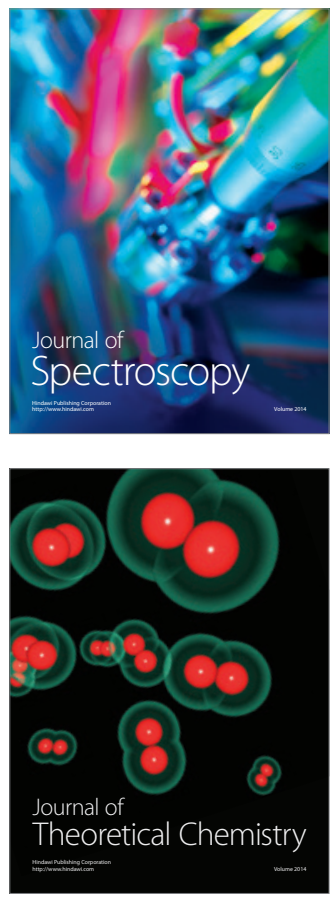
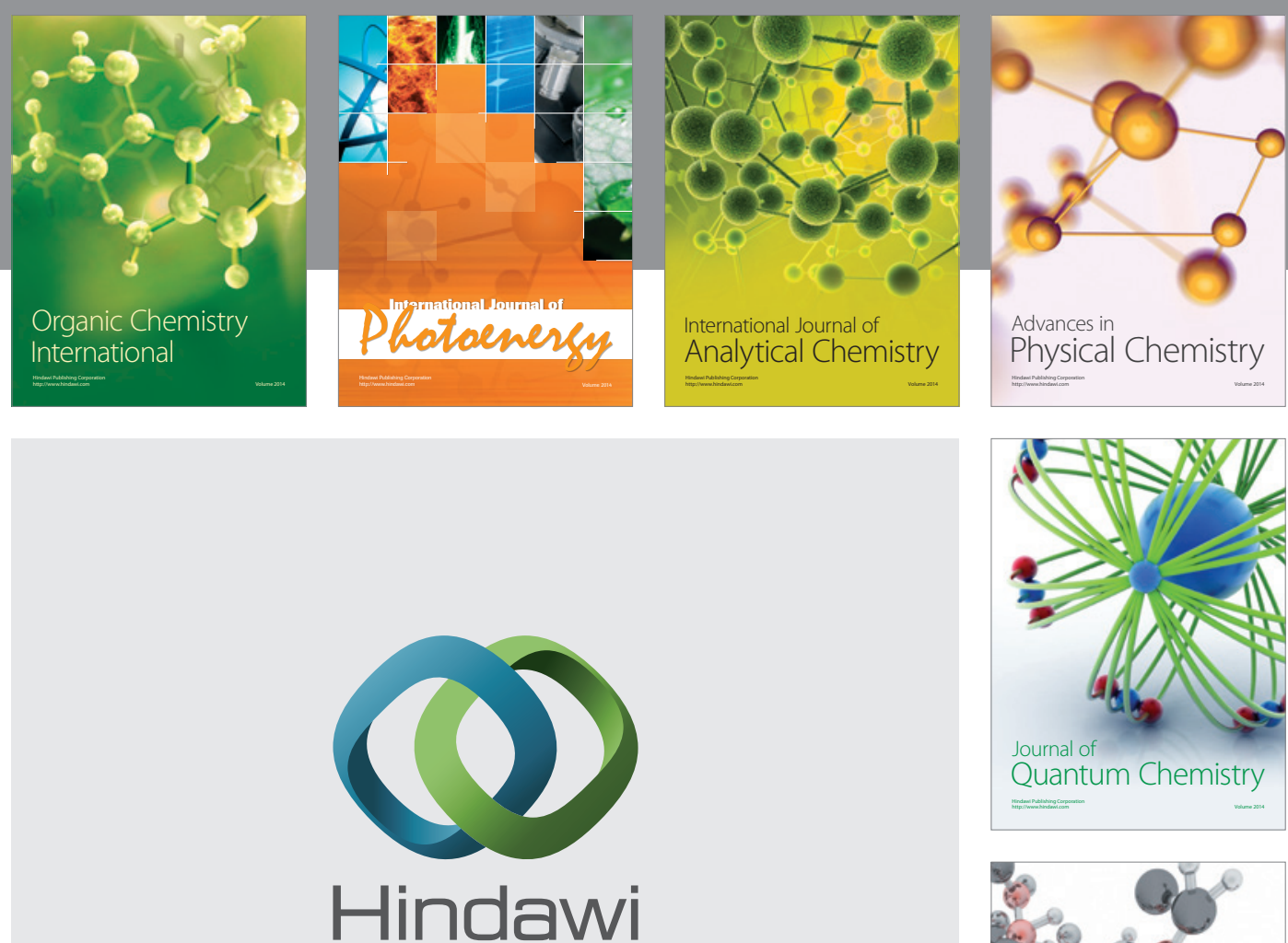

Submit your manuscripts at

http://www.hindawi.com

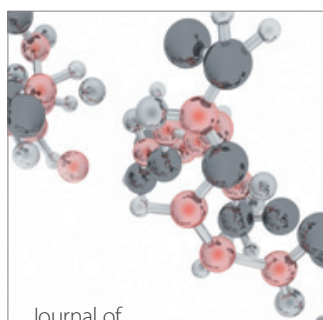

Analytical Methods

in Chemistry

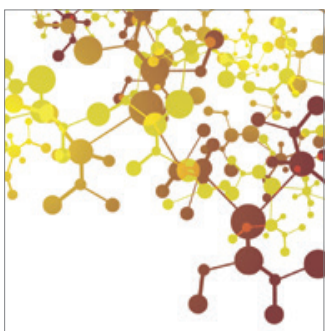

Journal of

Applied Chemistry

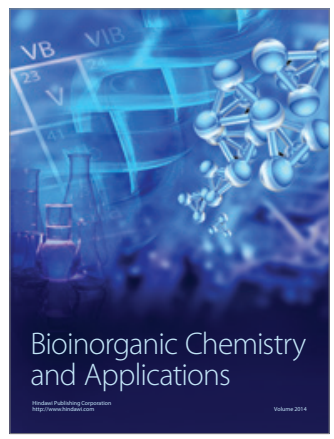

Inorganic Chemistry
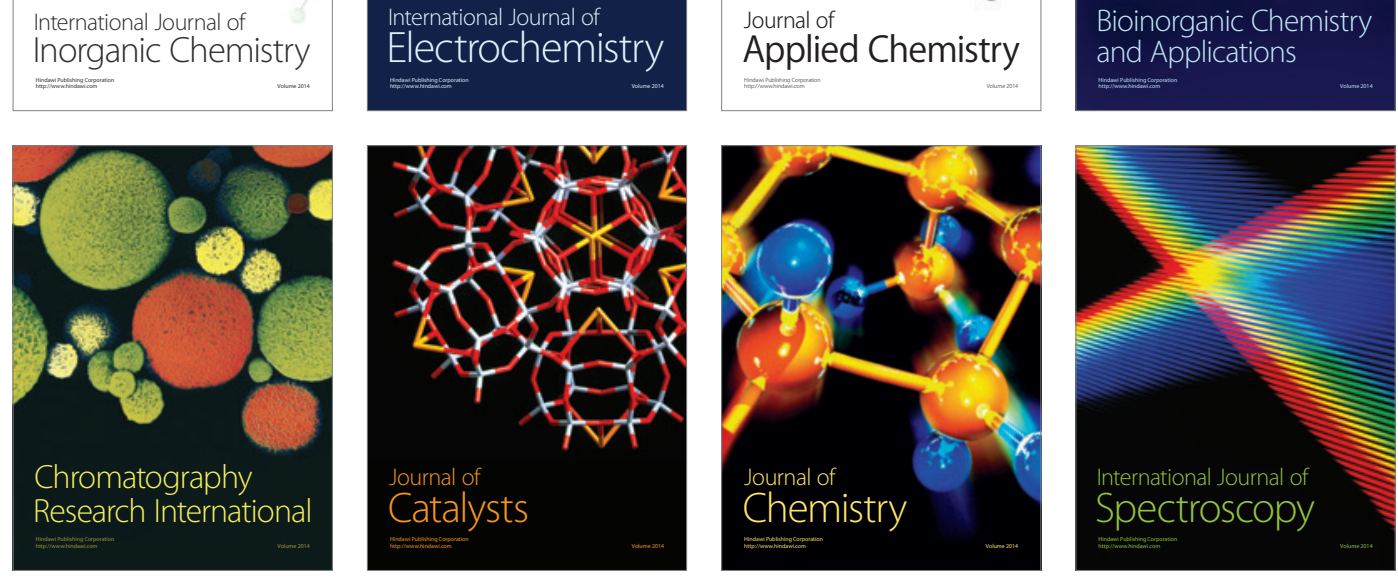